\title{
The BCS Appathon Challenge at Greenwich
}

Yasmine Arafa, Cornelia Boldyreff, Asif Malik, Andy Wicks, Gillian Windall, University of Greenwich

\section{Abstract}

The BCS Appathon set out to engage during one hour as many people as possible in the UK in programming an app for their mobile phones. It took place on the 9th June 2015, between 10.30 and 11.30, at a number of UK venues, one of which was the University of Greenwich.

Many people now rely on their mobile phones and, daily, use a variety of apps on them, but few have any knowledge of how an app has been developed. The Appathon aimed not merely to give participants an understanding of app development - its ambitious aim was to get participants to create their own simple app during a one-hour, highly-interactive workshop. The workshop then continued on into the afternoon, allowing Appathon attendees to work individually or in small groups, developing apps of their own design. In the concluding session, participants had the opportunity to present their apps in a recorded show-and-tell activity. The apps developed ranged from simple games to such novel applications as an app to count the number of revolutions completed by a figure skater.

The success of the Appathon has encouraged staff in the Department of Computing and Information Sciences at Greenwich to consider how it could be deployed to first-year students, who, although they may well be active smart phone users, may also find programming difficult and lack confidence when starting to learn how to do it. We are also investigating how the Appathon can be used to engage students in schools and develop their interest in studying Computer and Information Sciences. By putting first-year students through the Appathon experience, we hope to create a large pool of student ambassadors who can work with us in taking the Appathon to local schools and using it as a taster event at our open days.

\section{Introduction and Background}

The BCS, The Chartered Institute for IT, has the goal of making IT good for society. The Royal Charter of the BCS defines one of its objectives: "to promote the study and practice of Computing and to advance knowledge and education therein for the benefit of the public" (BCS Royal Charter, 1984). Within the remit, BCSWomen, the specialist group for women members of the BCS, decided to hold workshops throughout the UK to give the public an insight into how the apps on their smart phones had been developed and to get them programming a simple app. Thus the BCS Appathon was conceived by members of BCSWomen. It grew from planning a workshop as a simple family fun day of programming to an effort to run, throughout the UK, simultaneous workshops, called Appathons, and to attempt to establish a Guinness World Record for "Most number of people simultaneously learning to code across multiple sites" [World record attempt: Ref. No. BCSWomen $150227123013 \mathrm{mnop}]$.

All of the learning materials used at the Appathon workshop were developed to get people with little or no programming experience developing Mobile phone apps. The first BCSWomen mobile programming workshop was developed by Dr Hannah Dee and Dr 
Karen Petrie. Dr Dee later refined and developed the workshop's resources and has made them available on the web. As all her materials have been released under a Creative Commons license, they are freely available (Dee, 2015a). In addition, in preparation for the BCS Appathon, she also prepared a number of associated 'Train the Trainer' videos and exercises for people leading the workshops at each Appathon site (Dee, 2015b).

On the 9th June 2015, over thirty sites took part in the BCS Appathon and the University of Greenwich was one of the largest, with over fifty people participating there. A video of the one-hour long lesson which started off the Appathon at Greenwich is available (Video Record, 2015); this was a requirement as evidence for the world record attempt.

\section{The Appathon Lesson Plan and its Delivery: the Big Meow}

The delivery of the official record attempt part was guided by a single lesson plan as well as a slide deck and an official BCSWomen Applnventor workshop handout (Dee, 2015c). All participants were given a USB containing the resources needed for the workshop. During the lesson, everyone had access to a laptop, tablet or smart phone, on which they could run the necessary software from a web browser to develop their app. The software used was MIT App Inventor (MIT App Inventor 'About Us', 2015). The development of App Inventor was coled by Professor Hal Abelson of MIT and Mark Friedman of Google in 2009. Other early women engineers from Google contributing to its development were Sharon Perl, Liz Looney and Ellen Spertus. App Inventor is easily accessible as a web service from MIT's Center for Mobile Learning. An ancestor of App Inventor is Scratch, which also uses a simple visual drag-and-drop approach to build up programs (Scratch). App Inventor's authors claim that its "simple graphical interface grants even an inexperienced novice the ability to create a basic, fully functional app within an hour or less". Certainly there is ample evidence for this claim, provided by number of people who took part successfully in the BCS Appathon. At the heart of the App Inventor project is a constructivist approach to education, as it seeks to help people move from being mere consumers of technology to be becoming creators of technology.

The official lesson plan covered the first hour and introduced people to the Android system and App Inventor by taking them through a simple exercise to develop an app. Using App Inventor and working individually or in pairs, participants designed the visual frontend of their app, by placing a button on the screen of the app and uploading a picture of cat to the button. They then attached a sound to the screen and associated a cat sound to it. (Figure 1 below illustrates a screen developed and shows the Applnventor Designer mode.) At this point, the appearance of the app was complete and all that remained was for the underlying code to be developed. In conventional software development, the interface to the user and the program's underlying logic are coded together in the same high-level language. By separating these two aspects of development, Applnventor supports a separation of concerns between what the users see and what goes on behind the screens, making it easier for novice programmers to develop applications. In Applnventor, an app may have several interconnected screens and each screen will have blocks of code associated with it.

The next step was to code the app using the simple visual programming blocks. The instructor took participants through this process step by step. The simple program was event-driven and consisted of the block illustrated in the screen shot in Figure 2 below, taken 
from App Inventor in the Blocks mode. Together, these two figures give a complete picture of the app that was developed during the lesson.

Figure 1: Cat Button Screen in Designer

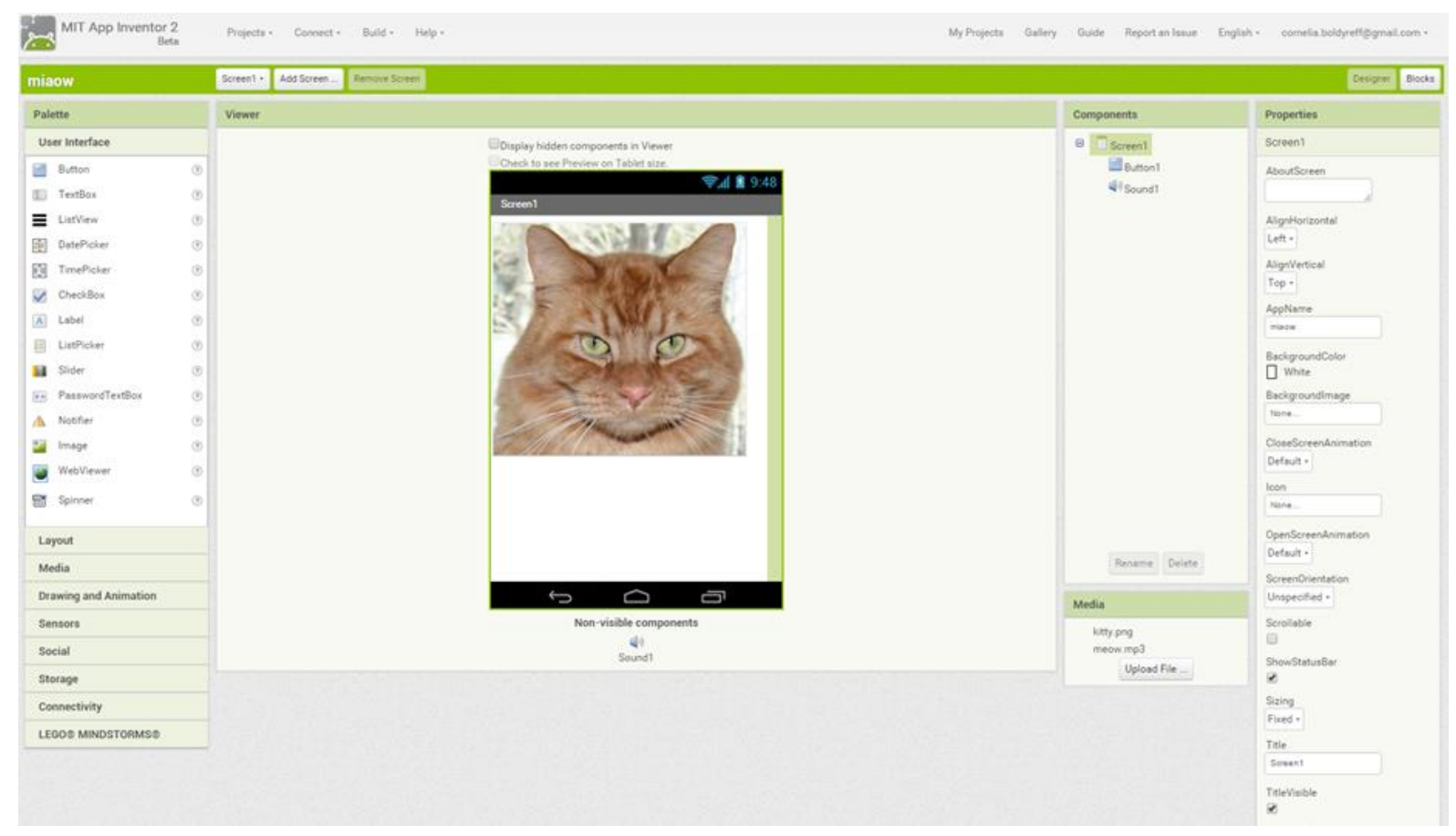

Figure 2: Code Block in Blocks

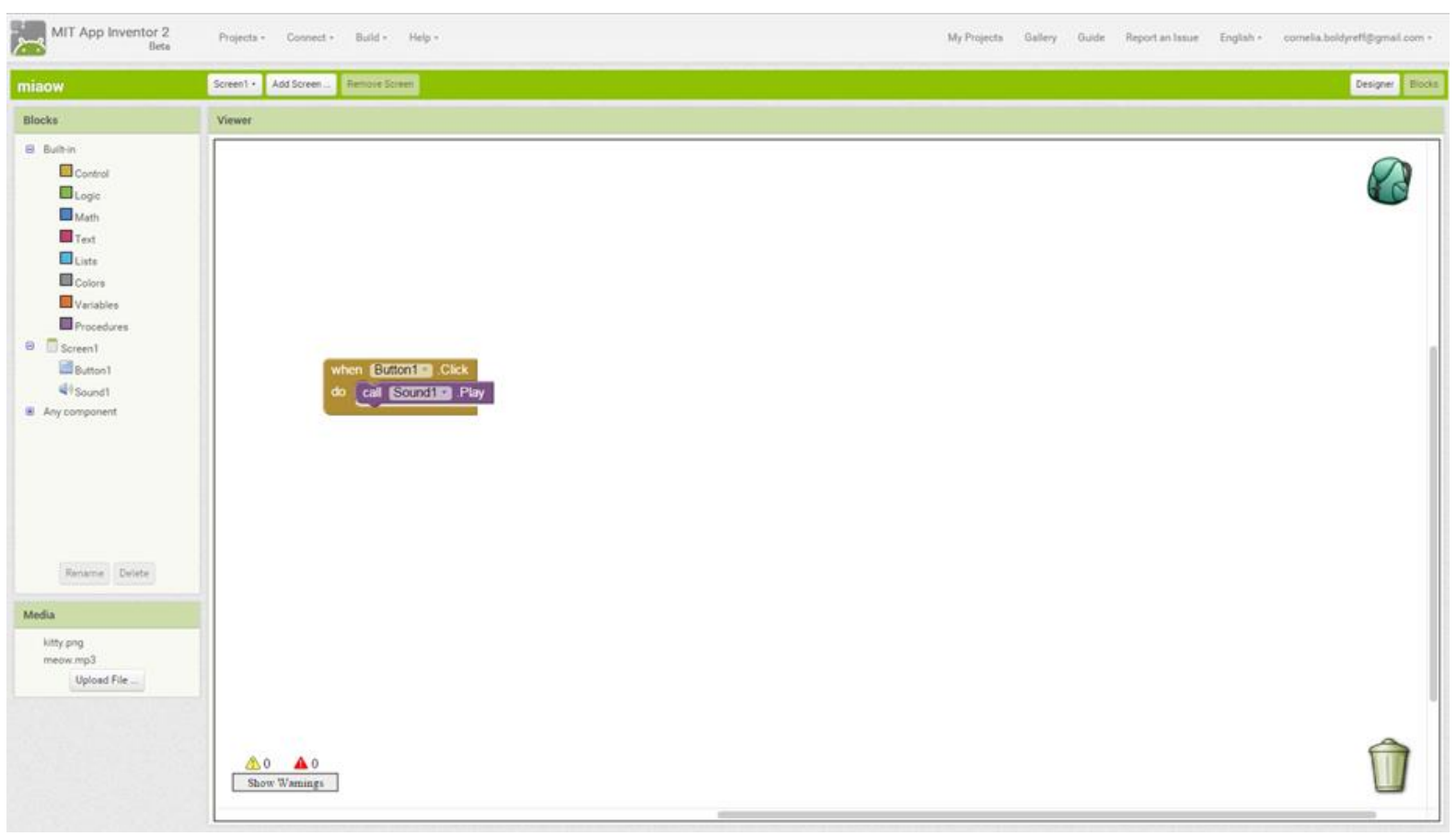


Finally, participants were in a position to build and download their apps to their phones or tablets and test them. The lesson covered how to do this and, for those without an Android device, an Android phone simulator was made available. At this point, as apps were successfully downloaded, the classroom began to fill with the sound of cats meowing. More adventurous students quickly began to adapt their programs, using different animal images and sounds provided on the USB Appathon resource sticks that all participants had received.

At the University of Greenwich, comprising the just over fifty people who took part were students, staff, families and members of the general public. The age of the participants ranged from six to the late sixties. The Appathon was open to all. The principal organisers and helpers were all members of university staff from the Department of Computer and Information Sciences. There were also independent witnesses and monitors present as the Appathon at Greenwich was part of the wider initiative to set a Guinness World Record. Throughout the UK during the Appathon, the same lesson plan and slides were employed to deliver the workshop. At each site, an official video recording of the proceedings was made and official photographs were taken.

As the lesson at Greenwich took place in a classroom with students seated in rows of desks, there was plenty of opportunity for participants to work together in pairs or small groups. Parents and children sitting together were able to learn together. Many children and adults were observed coding together throughout the lesson and workshop sessions that followed. It could be argued that the mixed ages of participants was a positive advantage, allowing them to learn from each other as well as from the instructor and official helpers.

The lesson concluded with a massive Meow-athon as the final whistle was blown, signalling the end of official lesson and its recording for the world record attempt. This can be heard on the video.

\section{What came next: Apps developed on the day at Greenwich}

The workshop continued until late afternoon. There was a lunch break, although some participants had brought food with them and, such was their enthusiasm once they got started, they continued working throughout lunch on their own app developments. Helpers were available throughout the workshop to assist participants with any problems and help them with their developments.

The apps developed during the later workshop sessions were quite varied. The workshop ended with a show-and-tell session, during which people presented the apps that they had been producing. The photographs below in Figure 3 illustrate the range of apps created on the day: drawing apps, a phone-to-phone messaging app, a thimble game and an app to count revolutions for figure skaters. 
Figure 3: Apps developed at Greenwich

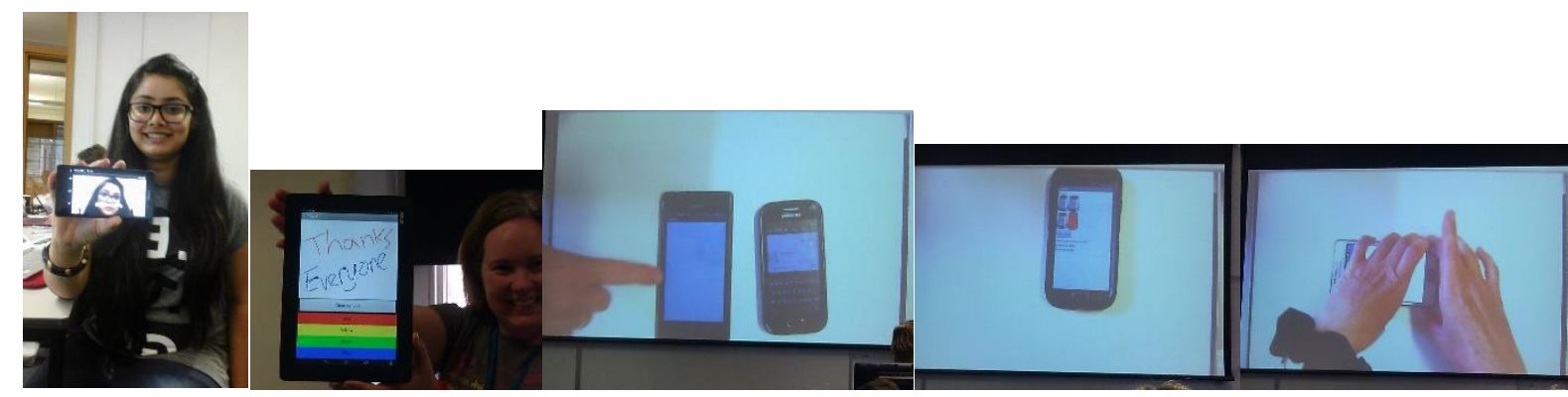

The success of the event at Greenwich was evident from both the formal and informal responses we got on the day and after the event; for example, the participant who developed the app for skaters remarked in an email after the event:

"I was very impressed by the range of different apps people came up with - it shows how much you can do (and how far we've come since the days of punch cards! ;-)).

"I've noticed the database facility in App Inventor, which will be handy when I come to calculating average/max no of spins and spinning speeds (:)

l'm going skating tonight so l'll do a test of my app." (quoted with permission from the respondent).

Nationwide, over 1000 people took part in the Appathon, so we at Greenwich were happy to have our fifty participants included in the count towards the official world record (Computer Weekly, June 2015).

\section{Future Plans to take the Appathon to schools with student support}

The success of the Appathon has encouraged staff in the department to think of how it could be deployed to first-year students, who, although they may well be active smart phone users, may also find programming difficult and lack confidence when starting to learn how to do it. We are also investigating how the Appathon can be used to engage students in schools and develop their interest in studying Computer and Information Sciences. By putting first-year students through the Appathon experience, we hope to create a large pool of student ambassadors who can work with us in taking the Appathon to local schools and using it as a taster event at our open days.

Although many students have done some programming prior to joining the Computer and Information Systems (CIS) Department, few claim to be confident programmers; in a survey of all first-year students at the start of the academic year 2015-16, Malik and Wicks found that although $74.9 \%$ had done programming before coming to university, only $3.4 \%$ claimed to be confident programmers (unpublished data). All students on the department's degree programmes study programming in their first year; it is a challenge that many first years find very difficult and, in CIS, one member of staff has produced a very popular series of videos for students entitled: Why is programming hard? (Wicks, 2014). 
In our recently-started project, working with GreenwichConnect (Greenwich Connect Blog), we plan to investigate whether we can kickstart students' enthusiasm for programming by using the one-day Appathon material, suitably adapted. We envisage that, following the Appathon experience, the student teams formed to develop apps will not only build individual members' confidence to tackle the programming module in the first year, but also provide a cohort of supportive peers. To encourage student teams beyond the first workshop, we intend to support them to submit their apps to the App Store and, at the end of first year, we shall offer prizes, based on user feedback and numbers of downloads recorded online, for the most popular apps. This competition will be linked to our formation of the Greenwich University student chapter of the BCS, which all students will be encouraged to join in their first year. Membership of a professional society will contribute to students' employability, giving them entry into the leading chartered institute for IT professionals in the UK (BCS Student Chapters).

To support students, Andy Wick's videos will be adapted by the project team and additional material on team working in app development will be introduced. Experience and evidence of working in teams is a positive factor when students seek employment, as many of our students do during their studies; relevant programming experience enables students to take on technical work related to their studies.

With the assistance from a Greenwich Connect learning technologist, we shall be developing online support for our student teams to work collaboratively throughout the year in an activity which will be essentially extra-curricular; nevertheless, we hope it will enable them individually to pass their first-year programming module, to gain experience of working in teams (something required by course work in other modules) and prepare them for their professional work in the future.

We are also investigating how the Appathon can be used to engage students in schools and develop their interest in studying Computer and Information Sciences. By putting first-year students through the Appathon experience, we hope to create a large pool of student ambassadors who can work with us in taking the Appathon to local schools and using it as a taster event at our open days.

\section{Conclusions}

The success of the BCS Appathon at Greenwich has inspired us to aim at giving all our firstyear students a chance to experience the challenge of the Appathon and the thrill of creating their own apps. Of course, the dream of many Computer and Information Sciences students, once they become app developers, is to create a killer app and make their fortune. Though that may not be possible for every student learning to create an app with App Inventor, it is the case that, through the Appathon experience, many more people have gained a better understanding of apps and of the digital technology that is shaping our world today. Our students will have the potential to be in vanguard of the Digital Revolution.

\section{Reference list}

Bateman, K. (2015) 'BCSWomen hosts Guinness World Record attempt with marathon appbuilding event.' Computer Weekly, 16th June 2015. Available at: 
http://www.computerweekly.com/news/4500248183/BCSWomen-hosts-Guinness-WorldRecord-attempt-with-marathon-app-building-event (Accessed: 22 April 2016).

BCS Royal Charter (1984) Available at: http://www.bcs.org/upload/pdf/royalcharter.pdf (Accessed: 22 April 2016).

BCS Student Chapters webpage. Available at: http://www.bcs.org/category/18176 (Accessed: 22 April 2016).

Dee, H. (2015a) 'BCSWomen Appinentor Family Fun day workshop.' Available at: http://www.hannahdee.eu/appinventor/ (Accessed: 22 April 2016).

Dee, H.( 2015b) 'Train the trainers.' [exercises and videos] Available at: http://users.aber.ac.uk/hmd1/appinventor/ttt.html (Accessed: 22 April 2016).

Dee, H. (2015c) 'Android Programming "Family Fun Day" using Applnventor.' Available at: http://www.hannahdee.eu/appinventor/appinventor handout2.0.pdf (Accessed: 22 April 2016).

Greenwich Connect Blog. Available at: http://blogs.gre.ac.uk/greenwichconnect/ (Accessed: 22 April 2016)

MIT App Inventor "About Us" webpage. (2012-2015) Available at: http://appinventor.mit.edu/explore/about-us.html (Accessed: 22 April 2016).

Scratch webpage. [Scratch is a project of the Lifelong Kindergarten Group at the MIT Media Lab.] Available at: https://scratch.mit.edu/ (Accessed: 22 April 2016).

Video Record of the BCSWomen Appathon at the University of Greenwich on 13 June 2015 (2015) Recorded by Taylor, Conrad. Available at: https://www.youtube.com/watch?v=aJGJofaRxc\&feature=youtu.be (Accessed: 22 April 2016).

Wicks, A. (2014) Why is programming hard? [Series of videos on YouTube.] Part 1 available at: https://www.youtube.com/watch?v=BRaBWlcAqlQ (Accessed: 22 April 2016). 